\title{
PORTO-CAVAL AND PORTO-PULMONARY ANASTOMOSES IN LAENNEC'S CIRRHOSIS AND IN HEART FAILURE ${ }^{1}$
}

\author{
By PAUL CALABRESI 2 AND WALTER H. ABELMANN 3 \\ (From the Thorndike Memorial Laboratory, the Second and Fourth [Harvard] Medical Serv- \\ ices and the Mallory Institute of Pathology, Boston City Hospital, and the Depart- \\ ment of Medicine, Harvard Medical School, Boston, Mass.)
}

(Submitted for publication February 1, 1957; accepted April 18, 1957)

Unsaturation of arterial blood for oxygen in patients with cirrhosis of the liver was first reported by Snell (1) and has been confirmed in this laboratory (2). This was found to be associated with a low partial pressure of oxygen in arterial blood in the absence of any defect of alveolar-capillary diffusion (3). These findings indicated an abnormally large venous admixture, attributable either to uneven ventilation-perfusion relationships or to anatomical shunts by-passing the lungs.

Anastomoses between the portal venous system and the superior caval system are known to be prominent in patients with hepatic disease and portal hypertension. Inasmuch as anastomoses between the pulmonary veins, bronchial veins, and azygos veins have also been demonstrated (4-8), it appeared possible that anastomotic channels between the portal venous system and the pulmonary venous system might exist. These, in the presence of portal hypertension, might lead to admixture of unsaturated portal venous blood to oxygenated pulmonary venous blood. This hypothesis was tested anatomically by means of injection of the portal venous system in human cadavers.

\section{MATERIAL AND METHODS}

In 20 human cadavers, prior to routine post-mortem examination, the portal vein was injected in situ with a radiopaque lead-gelatin mass, a modified Schlesinger mixture (9), which does not enter vessels less than $40 \mu$ in diameter. Methyl-green dye was added to the mass, which was injected under pressure of 7 to $10 \mathrm{~cm}$. $\mathrm{Hg}$. In order to obtain optimal filling of the vascular tree under study, the following vessels were ligated (Figure 1): the portal vein at the porta hepatis, the superior and inferior

1 Aided by grants from the Massachusetts Heart Association and the Life Insurance Medical Research Fund.

2 Presently Field Investigator, National Cancer Institute.

${ }^{3}$ Established Investigator of the American Heart Association. mesenteric veins, the splenic vessels, and both venae cavae at the right atrium. The aorta and the pulmonary artery were ligated at their point of origin.

After the mass had hardened, the viscera were removed en bloc. In several instances radiograms of the block were made before dissection. Sketches and color photographs at successive stages of the dissection permitted subsequent analysis and comparison of the injected vessels.

In general, $400 \mathrm{ml}$. was the optimal amount of mass. In five cases (Nos. 1-3, 11, 17) less than $350 \mathrm{ml}$. of mass was injected. In Cases 2 and 3 the amount was adequate to fill the portal venous system and the injection was considered satisfactory, while in three cases (Nos. 1, $11,17)$ it failed to fill the portal venous system but could not be extended for technical reasons. In Case 8 , where death was due to rupture of esophageal varices, the mass entered the esophagus freely, preventing filling of any mediastinal collateral channels that may have existed.

The material was divided into three groups (Table I).

Group I consisted of 10 cases of cirrhosis of the liver. All cases in this group had clinical evidence of hepatic decompensation and ascites, which exceeded 5 liters in six cases. Pathologically the patients all had classical Laennec's cirrhosis except for Case 6 whose liver showed "healed acute yellow atrophy." This was the only patient without history of alcoholism.

Group II comprised six cases of heart failure. The etiology of heart disease is indicated in Table I. Significant chronic passive congestion of the liver was present in five cases, of which two showed central hemorrhagic necrosis of the liver (Nos. 12 and 16) and one (No. 15) had cardiac cirrhosis: a patient with mitral stenosis and tricuspid insufficiency who had been in right heart failure for several years.

Group III included four cases without evidence of functionally significant hepatic or cardiac disease. The liver was structurally normal in all cases. Focal myocardial fibrosis was present in Cases 17 and 19, and the coronary arteries of Case 17 showed some sclerosis.

\section{RESULTS}

\section{Group I}

In all cases of cirrhosis, peri-esophageal veins (Figures 2 and 3 ) were observed to be injected via the short gastric and coronary veins and extended 
TABLE I

Localization of indicator material after injection into the portal vein

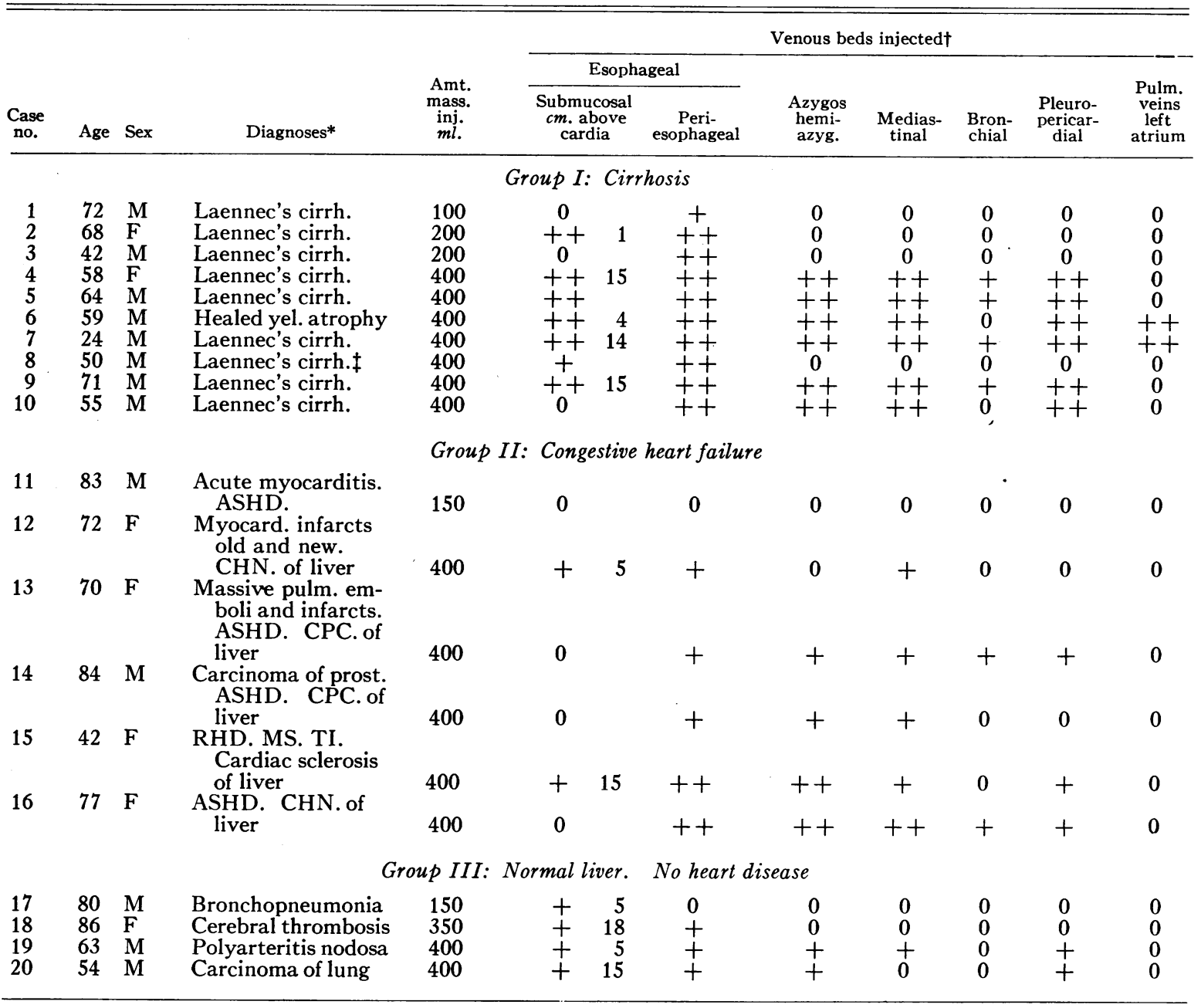

* ASHD. = Arteriosclerotic heart disease. $\mathrm{CHN} .=$ Central hemorrhagic necrosis. $\mathrm{CPC}$. = Chronic passive congestion. MS. = Mitral stenosis. RHD. = Rheumatic heart disease. TI. = Tricuspid insufficiency.

$+0=$ No injection $+=$ injected $;++=$ prominently injected.

$\ddagger$ Cause of death: Rupture of esophageal varices. Injection mass in lumen of esophagus and stomach.

above the level of the carina. These veins were dilated and tortuous. They anastomosed freely with mediastinal veins and, through these, with pleuro-pericardial veins and quite prominently with the azygos and hemi-azygos veins (Figure 3 ) and through these with the superior vena cava. This venous network was demonstrated whenever the amount of injection mass was adequate except in Case 8 where the mass entered the esophagus from ruptured submucosal varices.

In four of the six full injections the posterior mediastinal veins anastomosed freely with peribronchial venules at the tracheal bifurcation and, through these, with bronchial veins of the mainstem bronchi, most prominently about the right main-stem bronchus. On one occasion (No. 7) several large mediastinal veins communicated with the hilus of the right lung, and one was followed to its termination in a pulmonary vein (Figure 3 ).

In two of the fully injected specimens (Nos. 6 and 7) the mass was found in the pulmonary veins, left atrium and left ventricle, while the right ventricle and aorta were free of mass.

Submucosal esophageal veins were found to be injected in 7 of the 10 cirrhotics. They were dilated and tortuous, i.e., varicose, in six of these 


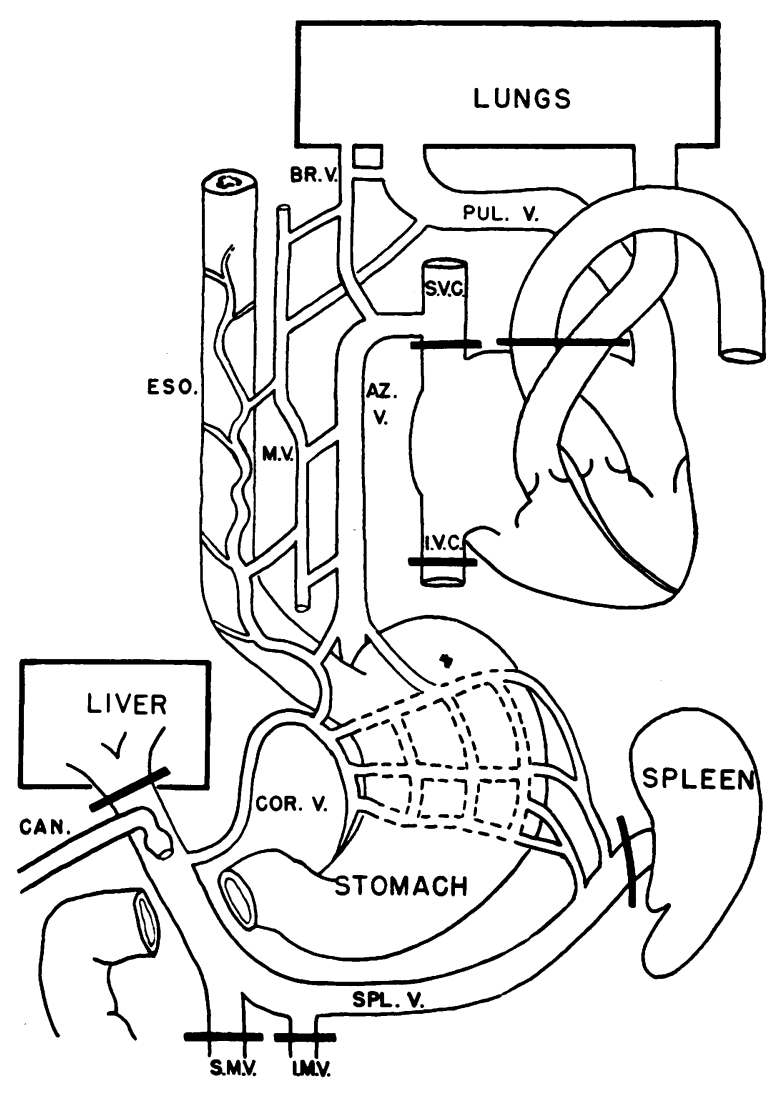

Fig. 1. Schematic Representation of the Plan of Injection, Showing the Principal Collateral Channels in the Portal, Mediastinal and Pulmonary Venous Beds

The heavy straight lines indicate ligatures.

Can., injection cannula; Eso., esophagus with periesophageal veins; M.V., mediastinal veins; Br.V., bronchial veins; Cor.V., coronary vein; Pul.V., pulmonary vein; S.V.C., superior vena cava; I.V.C., inferior vena cava; S.M.V., superior mesenteric vein; I.M.V., inferior mesenteric vein; Spl.V., splenic vein; Az.V., azygos vein.

(Figure 2), but were poorly filled in the seventh, who showed a ruptured esophageal varix (No. 8). These veins showed great variation, extending from 1 to $15 \mathrm{~cm}$. above the cardia. There was no predictable relationship between the size or extent of submucosal esophageal veins and the extent of peri-esophageal veins. Moreover, gross communications between the two venous plexuses appeared sparse and were difficult to demonstrate. Periesophageal veins were often more prominent than submucosal veins, and were preferentially filled when the amount of mass injected into the portal vein was small.

\section{Group II}

Submucosal esophageal veins were demonstrated in only two of the five cases of congestive heart failure who were injected adequately, while peri-esophageal veins were demonstrated in all five, and were dilated and tortuous in two cases of severe heart failure (Nos. 15 and 16) (Figure 4). Gross anastomotic connections were again demonstrated between the peri-esophageal veins, mediastinal veins, and azygos or hemi-azygos veins (Figure 4). From this venous network, bronchial venules and pleuro-pericardial venules filled in some instances. In no instance did injection mass appear in the pulmonary veins or left atrium.

\section{Group III}

In all four of the subjects without hepatic disease or congestive heart failure submucosal esophageal veins were visualized extending 5 to $18 \mathrm{~cm}$. upward from the cardia. Peri-esophageal veins were injected in all except No. 17 in which the amount of mass delivered was small. In some instances, mediastinal, pleuro-pericardial, and azygos veins were injected (Figure 5), but these channels never reached the number or size encountered in Groups I and II.

\section{DISCUSSION}

\section{Anatomical considerations}

Injection of a mass, which does not penetrate capillary networks, has demonstrated anastomoses of the portal venous bed with the superior vena cava through peri-esophageal, mediastinal, and azygos veins. These porto-caval anastomoses were strikingly more numerous and larger in cases with presumptive prolonged hypertension in either the portal venous system or the caval venous system. Portal hypertension was associated with the most prominent anastomotic channels. Small anastomotic channels between the mediastinal veins and the bronchial venous system were also present in some cases. In two cases of portal hypertension, gross anastomoses between the portal venous system and the pulmonary venous system were demonstrated. Although such direct communications were not seen in the remainder of the present material, they have not been ruled out by the method used. 


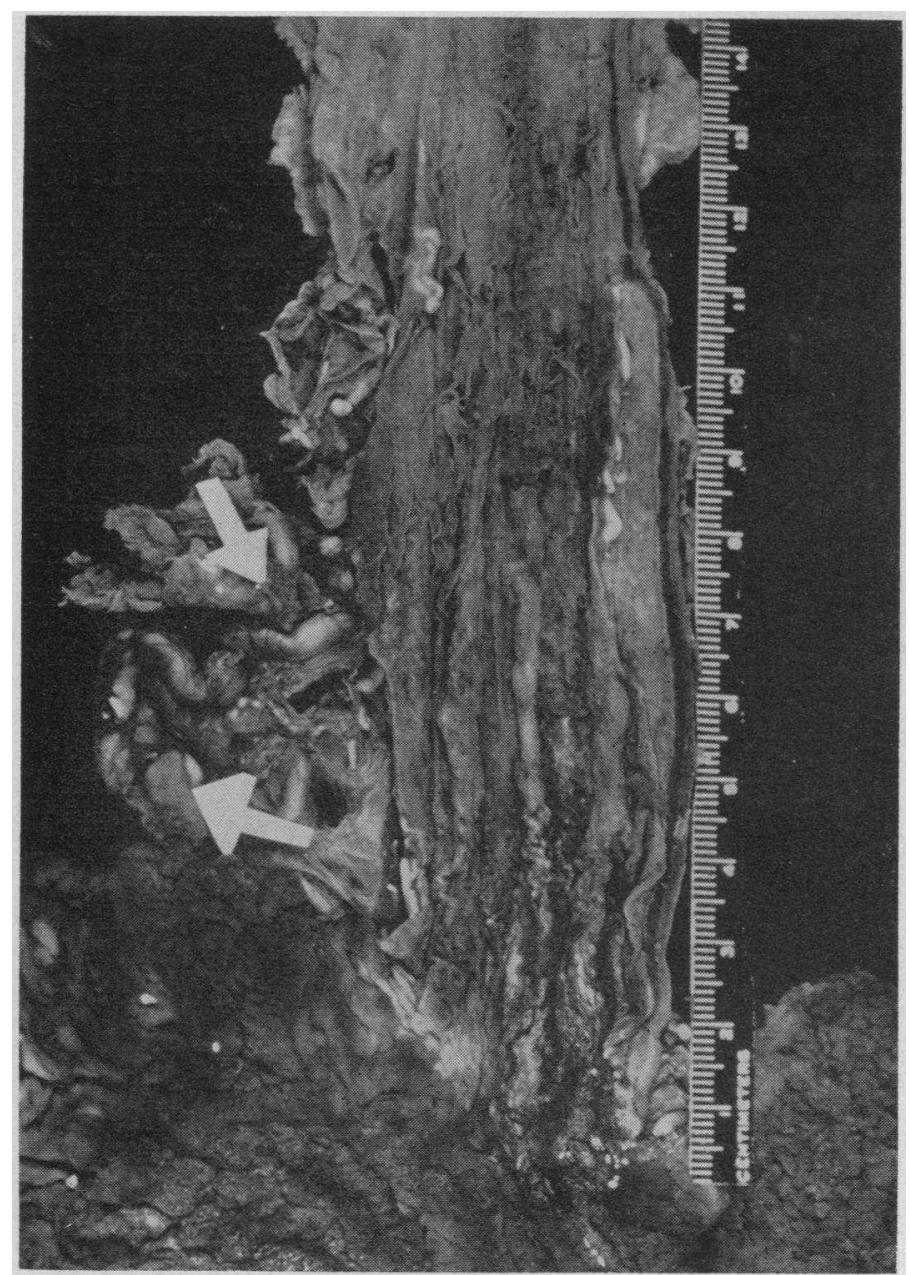

Fig. 2. Demonstration of Varices in Cirrhosis

Case No. 7. Cirrhosis. Mucosal surface of cardia (below) and esophagus. Submucosal esophageal varices are seen extending upward from the cardia. The arrows point to large peri-esophageal varices.

While the submucosal esophageal veins have been mentioned more prominently in the literature, undoubtedly because of their clinical importance, the presence of peri-esophageal veins and their predominance over submucosal veins in some cases of portal hypertension have been noted by others $(6,10-13)$. The present material supports the view that the peri-esophageal veins represent more likely paths of porto-caval shunts than the submucosal veins $(12,13)$.

Anastomoses between the peri-esophageal veins, mediastinal veins, bronchial veins and azygos veins have long been recognized $(4,14,15)$, as have been anastomoses between the pulmonary veins and the bronchial veins $(4,5,8)$. Liebow $(8)$ has reported a case in which mediastinal vessels communicated directly with a pulmonary vein and the left atrium.

Reports of injections of complete collateral pathways between the portal and the pulmonary venous system are fragmentary. Corning (16) states that gastric veins can be injected from the pulmonary veins without referring to the original work. Butler (6) injected India ink into the superior mesenteric vein of three foeti at term; in two the ink passed from the veins of the stomach into the subepithelial and submucosal veins of the lowermost esophagus, but entered the peri-esophageal veins to a much higher level, reaching the posterior bronchial veins and the azygos veins. 
More recently, Schoenmackers and Vieten (13) have published post-mortem portal angiograms of a case of cirrhosis which demonstrate passage of injection mass into pulmonary veins and left atrium, presumably by way of mediastinal veins. Their angiograms resemble radiograms taken of Case 7 in the present series. Blackburn (17) demonstrated a large porto-pulmonary venous anastomosis in a case of extrahepatic portal venous obstruction with portal hypertension and left ventricular hypertrophy and failure, which he attributed to a large porto-pulmonary shunt.

Major anomalous connections between the pul- monary venous system and the portal vein have been reported (18), but appear rare and have usually been associated with other cardiovascular anomalies and attributed to persistence of one or more of the primitive connections between the pulmonary and splanchnic systems of veins.

The fact that anastomotic connections have been demonstrated between the portal venous system and the superior caval system and between the latter and the pulmonary veins in essentially normal individuals suggests that the increased prominence of such anastomoses in disease represents a widening of pre-existing anastomotic channels.

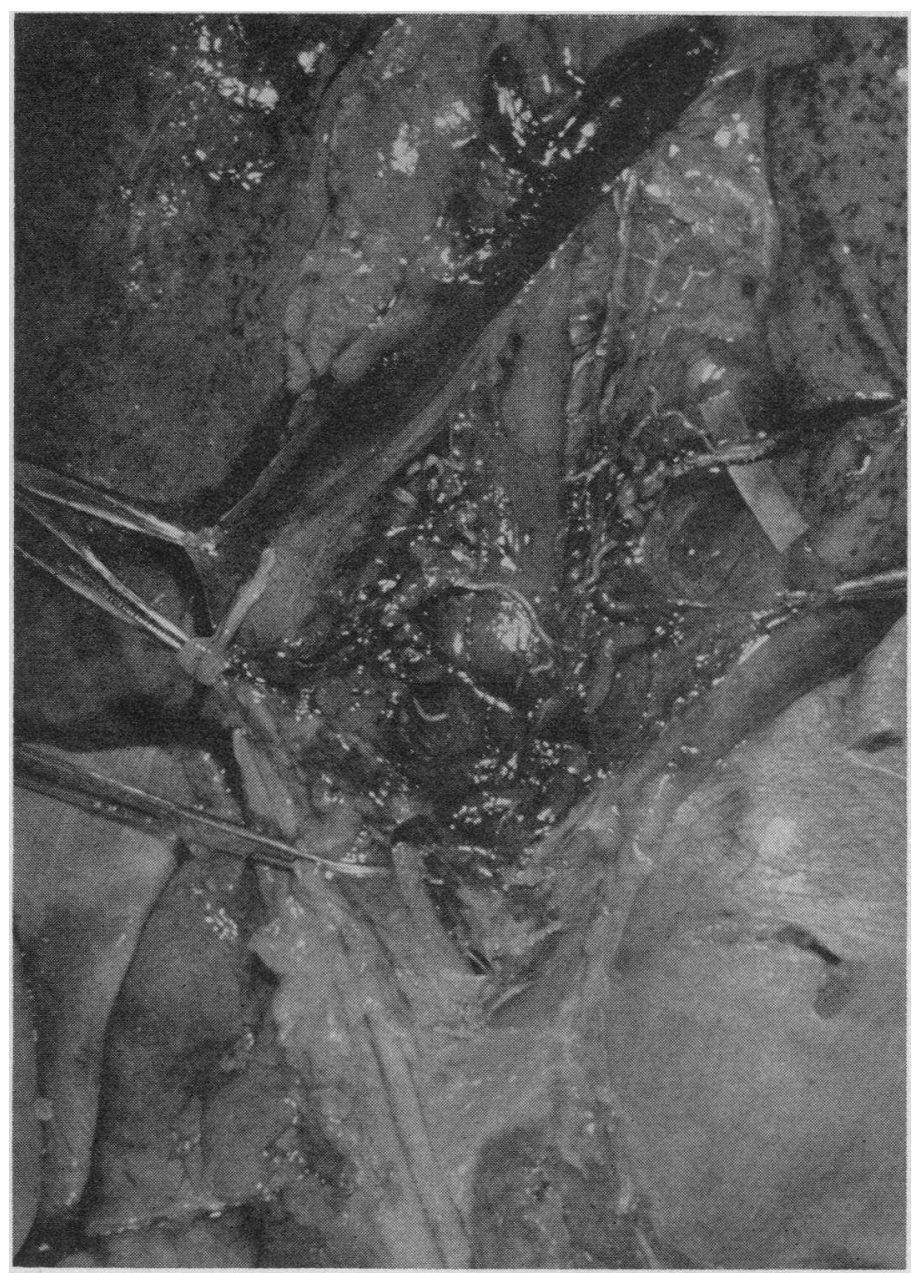

Fig. 3. Communication Between Esophageal and Azygos Veins in Cirrhosis

Case No. 7. Cirrhosis. Mediastinum and posterior aspect of esophagus with prominent peri-esophageal and mediastinal veins draining into the large azygos vein (retracted to the left). A piece of paper (on the right) identifies a vein connecting the mediastinal plexus to a right pulmonary vein. 


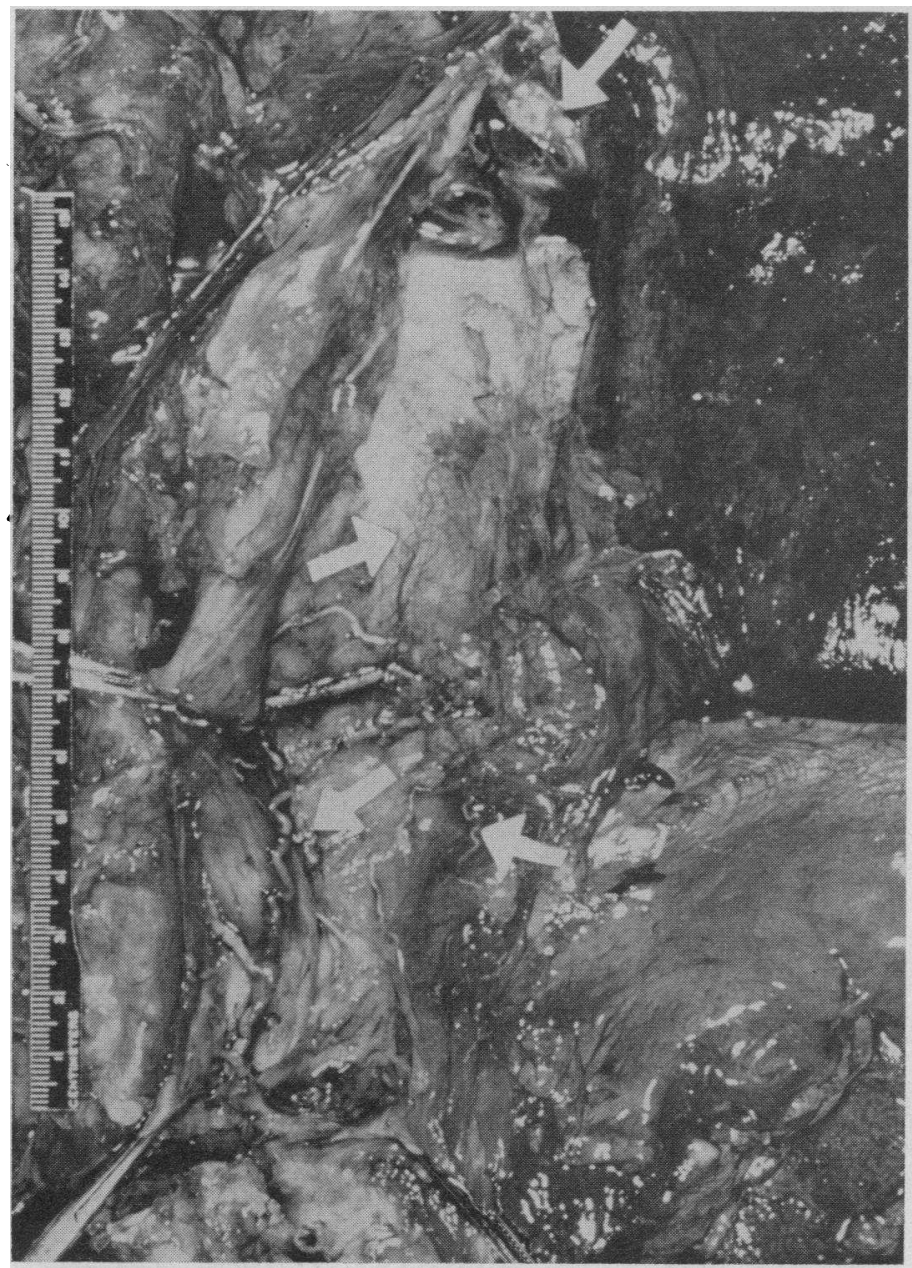

Fig. 4. Dilated Peri-Esophageal Veins in Congestive Fallure

Case No. 14. Congestive heart failure. Posterior mediastinum and esophagus (retracted to the left) with injected peri-esophageal and mediastinal veins.

Such channels should be demonstrable more frequently with suitable modification of injection technique including further limitation of the vascular bed and direct injection into the mediastinal veins or the left atrium.

\section{Physiological considerations}

Anatomical demonstration of collateral vascular channels by means of post-mortem injection does not necessarily prove that such pathways are ever functional, nor does it yield any information about the direction of possible blood flow. According to Butler (6) peri-esophageal veins are without valves, except at their entry into the azygos vein. Valves also have been demonstrated in the azygos vein at its entry into the superior vena cava. No valves are known to exist in mediastinal and bronchial veins, or in pulmonary veins. With the reservation that nothing is known about possible veno-motor activity in this region, consideration may now be given to the relative pressure relationships in the three venous beds concerned: the superior caval, the portal, and the pulmonary. Normally, the mean pressures in the pulmonary venous and portal venous systems are about equal $(19,20)$. Collateral flow is therefore unlikely although not impossible, since significant differences in pressure might arise during the respiratory cycle. While pulmonary venous pressure decreases with inspiration, McMichael (21) has 
shown that in the cat portal venous pressure rises with inspiration.

In patients with cirrhosis of the liver and portal hypertension, portal venous pressures have been found to range from 16 to $35 \mathrm{~mm}$. $\mathrm{Hg}$, with an average of $22 \mathrm{~mm}$. $\mathrm{Hg}$ (20). Assuming normal pulmonary venous pressure in such patients, a porto-pulmonary shunt is conceivable, especially if an increase in caval venous pressure should develop.

In patients with mitral stenosis or with left heart failure due to aortic valvular lesions, catheterization of the left heart has shown that pulmonary venous pressure may reach values comparable to those prevailing in the portal vein in cirrhosis (22). In such patients pulmo-caval and pulmo-portal shunts may conceivably exist.

The pressure in the pulmonary venous bed is probably higher than the pressure in the intrathoracic superior caval bed throughout most of the respiratory cycle (23). This relationship should favor drainage of the bronchial veins into the azygos system; yet the bronchial veins are generally thought to drain mainly into the pulmonary veins (24). However, in patients with mitral stenosis and pulmonary venous hypertension, Ferguson, Kobilak and Deitrick (25) found submucosal bronchial veins dilated and postulated that blood flow might be reversed, the bronchial venous system acting in effect to decompress the

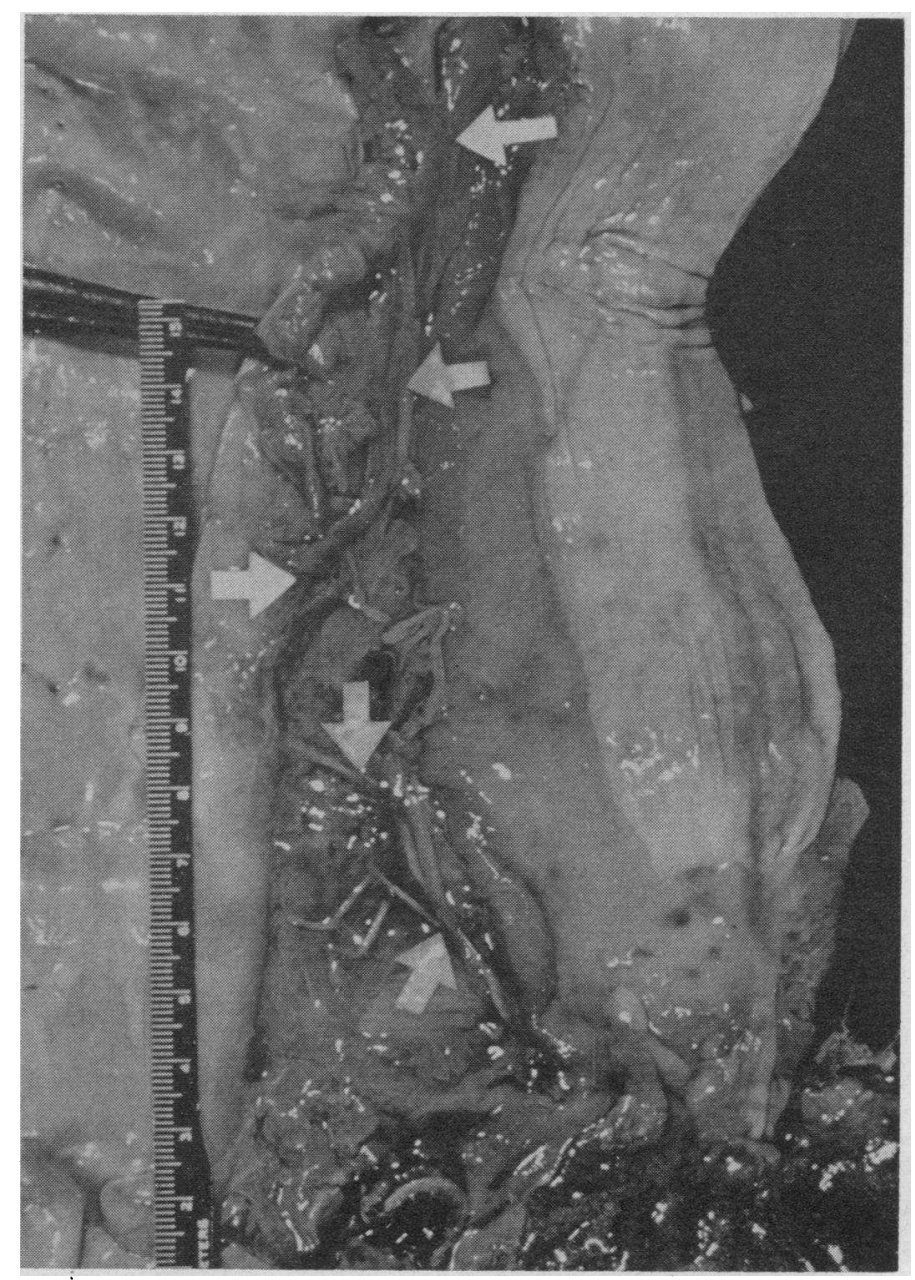

Fig. 5. Veins of the Normal Posterior Mediastinum

Case No. 19. Normal liver. No heart disease. Posterior mediastinal dissection showing injected veins between the esophagus (right) and the aorta (left). 
over-distended pulmonary venous system into the superior caval system.

Anastomotic pathways between the portal venous system and the pulmonary venous system have been demonstrated in patients with cirrhosis. With the pressure gradients known to exist between these two vascular beds, the venous admixture responsible for the unsaturation of arterial blood in these patients (3) may be due, at least in part, to porto-pulmonary shunts. Such shunts could account for the otherwise unexplained finding of Faloon, Auchincloss, Eich and Gilbert (26) that the ammonia level of arterial blood may exceed that of mixed venous blood in cirrhotic patients. They may possibly play a role in metastatic spread of infection or tumor. Further physiological implications will be discussed elsewhere (3).

\section{Clinical considerations}

The variability in presence and degree of esophageal varices in individual cirrhotic patients has led to much speculation. The present material suggests that the anatomical variation in the esophageal venous pattern determines the location and extent of varices in any given case.

The prominence of submucosal esophageal veins in two patients with heart failure is of interest in view of the clinical (27) and pathological (28) demonstration of esophageal varices in patients with heart failure. Increased right atrial and caval pressure in right heart failure is accompanied by an increase in portal venous pressure to or slightly above the level of right atrial pressure $(29,30)$. Thus it is not surprising that collateral channels between the portal and caval systems may be dilated. The direction of blood flow, if any, remains in the realm of speculation. It also remains a matter of conjecture whether the pathways discussed would permit blood to flow from the caval into the pulmonary venous system in pure right heart failure.

While prominence of the roentgenographic shadow of the azygos vein has been noted repeatedly in patients with congestive heart failure (31-33), only one report of prominence of this shadow in patients with portal hypertension (34) has come to the attention of the present authors. In 11 of the present cases, chest roentgenograms taken during life were available and technically satisfactory for review. In five cases of cirrhosis (Nos. 2, 4, 7, 8 and 10) and in four cases of congestive heart failure (Nos. 11, 13, 15 and 16) the shadow of the azygos vein was enlarged according to the criteria of Fleischner and Udis (33); it was normal in two of the control cases (Nos. 17 and 20). Enlargement of the azygos vein presumably reflects caval venous hypertension, increased blood volume, or increased azygos flow from portal venous collaterals. Thus roentgenographic demonstration of an enlarged azygos vein may have clinical value.

\section{SUM MARY}

In order to study thoracic anastomoses of the portal venous system, the portal vein was injected in 20 human cadavers, including 10 with advanced cirrhosis of the liver and six with congestive heart failure.

In all cases of cirrhosis, thoracic porto-caval anastomoses were very prominent: the short gastric and coronary veins anastomosed with both the submucosal esophageal and peri-esophageal venous plexi. Although the submucosal esophageal veins were generally varicose, they showed great variation in their extent above the cardia. The periesophageal plexus, on the other hand, was consistently dilated and anastomosed freely with mediastinal, pleuro-pericardial and azygos veins. In four cirrhotics the mediastinal venous plexus showed anastomoses with bronchial veins, and in two cases injected material was present in the pulmonary veins and in the left atrium. Thus both porto-caval and porto-pulmonary anastomoses may exist in cirrhosis with portal hypertension.

Similar venous pathways were demonstrated in six cases of heart failure and in four cases having neither cirrhosis nor heart failure, but they were generally less prominent and the pulmonary veins did not fill with mass in these cases.

It is concluded that, in addition to the recognized porto-caval anastomoses, porto-pulmonary anastomoses may exist. When the pressure gradient between portal and pulmonary veins becomes significant, it is conceivable that these anastomoses may act as porto-pulmonary shunts, bypassing the lungs and reducing the oxygen saturation of arterial blood. 


\section{ACKNOWLEDGMENTS}

We are greatly indebted to Drs. K. L. Mallory, S. L. Robbins, and M. B. Bacaner for their generous cooperation in this study, and to Dr. F. Rodriquez y Legaspi for his advice on the injection technique.

\section{REFERENCES}

1. Snell, A. M., The effects of chronic disease of the liver on the composition and physicochemical propperties of blood: Changes in serum proteins; reduction in oxygen saturation of the arterial blood. Ann. Int. Med., 1935, 9, 690.

2. Abelmann, W. H., Verstraeten, J. M., Frank, N. R., McNeeley, W. F., and Kowalski, H. J., The alveolar-arterial oxygen pressure gradient in parenchymatous disease of the liver. Clin. Research Proc., 1954, 2, 47.

3. Abelmann, W. H., Kramer, G., Gravallese, M. A., Jr., and $\mathrm{McNeely}, \mathrm{W}$. F., Increased venous admixture in patients with cirrhosis of the liver and decreased arterial oxygen saturation, In preparation.

4. Zuckerkandl, E., Ueber die Anastomosen der Venae Pulmonales mit den Bronchialvenen und mit dem Mediastinalen Venennetze. Sitzungsb. d. k. Akad. d. Wissensch. Math.-naturw. C1., Abt. 3, 1882, 84, 110.

5. Marchand, P., Gilroy, J. C., and Wilson, V. H., An anatomical study of the bronchial vascular system and its variations in disease. Thorax, 1950, 5, 207.

6. Butler, H., The veins of the oesophagus. Thorax, 1951, 6, 276.

7. Tobin, C. E., The bronchial arteries and their connections with other vessels in the human lung. Surg., Gynec. \& Obst., 1952, 95, 741.

8. Liebow, A. A., The bronchopulmonary venous collateral circulation with special reference to emphysema. Am. J. Path., 1953, 29, 251.

9. Schlesinger, M. J., Personal communication, 1954.

10. Saxer, F., Beitraege zur Pathologie des PfortaderKreislaufs. Centralbl. f. allg. Path. u. path. Anat., 1902, 13, 577.

11. McIndoe, A. H., Vascular lesions of portal cirrhosis. Arch. Path., 1928, 5, 23.

12. Walker, R. M., Portal hypertension. Practitioner, 1949, 162, 211.

13. Schoenmackers, J., and Vieten, H., Archiv und Atlas der normalen und pathologischen Anatomie in typischen Roentgenbildern. Atlas post-mortaler Angiogramme. Fortschr. Geb. Roentgenstrahlen, 1954, Ergaenzungsbd. 69, 203.

14. Portal, A., Cours d'Anatomie médicale ou élémens de 1 'Anatomie de l'homme. Paris, Baudouin, 1803, 4, 533.

15. Konaschko, P. I., Ueber das System der Anastomosen die die Lungenvenen und den linken Vorhof mit den Venen des grossen Kreislaufs verbinden. Ztschr. Anat., 1929, 89, 672.
16. Corning, H. K., Lehrbuch der topographischen Anatomie fuer Studierende und Aerzte. Muenchen, J. F. Bergmann, 1942, p. 279.

17. Blackburn, C. R. B., Acquired portal-pulmonary venous anastomosis complicating partial oesophagogastrectomy in a patient with portal hypertension. Thorax, 1956, 11, 30.

18. Brody, $H$., Drainage of the pulmonary veins into the right side of the heart. Arch. Path., 1942, 33, 221.

19. Hellems, H. K., Haynes, F. W., and Dexter, L., Pulmonary "capillary" pressure in man. J. Applied Physiol., 1949, 2, 24.

20. Paton, A., Reynolds, T. B., and Sherlock, S., Assessment of portal venous hypertension by catheterisation of hepatic vein. Lancet, 1953, 264, 918.

21. McMichael, J., The portal circulation. I. The action of adrenaline and pituitary pressor extract. J. Physiol., 1932, 75, 241.

22. Abelmann, W. H., and Hancock, E. W., Unpublished observations, 1955.

23. Opdyke, D. F., and Brecher, G. A., Effect of normal and abnormal changes of intrathoracic pressure on effective right and left atrial pressures. Am. J. Physiol., 1950, 160, 556.

24. Miller, W. S., The Lung. Springfield, Ill., Charles C Thomas, 1947, pp. 79-88.

25. Ferguson, F. C., Kobilak, R. E., and Deitrick, J. E., Varices of the bronchial veins as a source of hemoptysis in mitral stenosis. Am. Heart J., 1944, 28, 445.

26. Faloon, W. W., Auchincloss, J. H., Eich, R., and Gilbert, R., Ammonia metabolism in cirrhotic patients with portacaval shunts. J. Clin. Invest., 1956, 35, 701.

27. Palmer, E. D., and Brick, I. B., Esophageal varices in non-cirrhotic patients. Esophagoscopic study. Am. J. Med., 1954, 17, 641.

28. Weinberg, T., Observations on the occurrence of varices of the esophagus in routine autopsy material. Am. J. Clin. Path., 1949, 19, 554.

29. Wren, E. M., The portal venous pressure in organic heart disease. Am. Heart J., 1954, 48, 929.

30. Taylor, W. J., and Myers, J. D., Occlusive hepatic venous catheterization in the study of the normal liver, cirrhosis of the liver and noncirrhotic portal hypertension. Circulation, 1956, 13, 368.

31. Durieu, H., and Lequime, J., Aspects radiologiques de la veine azygos au cours de l'insuffisance cardiaque. Arch. d. mal. du coeur, 1938, 31, 609.

32. Gemignani, V., Il quadro radiologico stratigrafico dell'arco della vena grande azigos. Radiol. med., 1946, 32, 381.

33. Fleischner, F. G., and Udis, S. W., Dilatation of the azygos vein. A roentgen sign of venous engorgement. Am. J. Roentgenol., 1952, 67, 569.

34. Grilli, A., Indagine radiologica delle varici esofagee ed aumento dell'ombra della vena azigos nella stasi portale. Radiol. med., 1936, 23, 165. 